\title{
Positive Reactant lon Formation in High Kinetic Energy Ion Mobility Spectrometry (HiKE-IMS)
}

Maria Allers*1, Ansgar T. Kirk ${ }^{1}$, Manuel Eckermann ${ }^{1}$, Christoph Schaefer ${ }^{1}$, Duygu Erdogdu², Walter Wissdorf ${ }^{2}$, Thorsten Benter ${ }^{2}$, Stefan Zimmermann ${ }^{1}$

\author{
${ }^{1}$ Leibniz University Hannover, Institute of Electrical Engineering and Measurement Technology, Appelstraße 9a, \\ 30167 Hannover, Germany \\ ${ }^{2}$ Department of Physical and Theoretical Chemistry, University of Wuppertal, Gauss Str. 20, 42119 Wuppertal, \\ Germany
}

*Corresponding author: allers@geml.uni-hannover.de

Keywords: Kinetic modelling, positive reactant ion formation, corona discharge ionization, ion mobility spectrometry, high kinetic energy ion mobility spectrometry, HiKE-IMS, IMS

\begin{abstract}
In contrast to classical ion mobility spectrometers (IMS) operating at ambient pressure, the High Kinetic Energy Ion Mobility Spectrometer (HiKE-IMS) is operated at reduced pressures between $10-40 \mathrm{mbar}$ and higher reduced electric field strengths of up to $120 \mathrm{Td}$. Thus, the ion-molecule reactions occurring in the HiKE-IMS can significantly differ from those in classical ambient pressure IMS. In order to predict the ionization pathways of specific analyte molecules, a profound knowledge about the reactant ion species generated in HiKE-IMS and their dependence on the ionization conditions are essential. In this work, the formation of positive reactant ions in HiKE-IMS is investigated in detail. Based on kinetic and thermodynamic data from literature, the ion-molecule reactions are kinetically modeled. To verify the model, we present measurements of the reactant ion population and its dependence on the reduced electric field strength, the operating pressure and the water concentration in the sample gas. All of these parameters significantly affect the reactant ion population formed in HiKE-IMS.
\end{abstract}

\section{Introduction}

Ion mobility spectrometers (IMS) generate ions in a reaction region and separate the ions by their motion through a neutral gas under the influence of an electric field in a drift region. High Kinetic Energy IMS (HiKE-IMS) also generate ions in a reaction region, for example by corona discharge (CD) ionization, before they are separated in a drift region. However, in contrast to classical ambient pressure IMS, the HiKE-IMS is operated at a reduced pressure of $10-40 \mathrm{mbar}$ and reaches high reduced electric field strengths of up to $120 \mathrm{Td}$ in both the reaction region and the drift region ${ }^{1-3}$. The reduced electric field strength $E / N$ is the ratio of electric field strength $E$ to neutral molecule density $N$, usually given in units of Townsend (Td). In this context, the reduced field is a measure of the average ion kinetic energy resulting from acceleration in the electric field and deceleration by collisions with neutrals. According to Wannier ${ }^{4}$, this energy can be expressed in terms of an effective ion temperature $T_{\text {eff. }}$ Compared to ambient pressure IMS, the operation at reduced pressure and high reduced electric field strengths leads to a significant enhancement of the linear dynamic range and a strong decrease in chemical cross sensitivities, as known from proton transfer reaction mass spectrometers (PTR-MS) ${ }^{5}$. Furthermore, HiKE-IMS enables the ionization of compounds normally not detectable at ambient pressure due to the inhibition of clustering reactions ${ }^{2}$. Other major benefits are orthogonal ion separation using the field-dependent ion mobility (alpha-function) known from differential ion mobility spectrometers (DMS) ${ }^{6}$ and ion collision induced fragmentation for improved compound identification 7,8 . However, until now only limited knowledge about the occurring ion-molecule 
reactions in HiKE-IMS is available. Thus, to gain maximum benefit from HiKE-IMS, a profound knowledge about the occurring chemical processes during ionization is essential.

The ionization process in HiKE-IMS with corona discharge ionization source follows the principles of atmospheric pressure chemical ionization (APCI). Initially, reactant ions are generated by ionizing the main constituents of the sample gas. Subsequently, the ionization of analyte molecules is achieved through a reaction with these reactant ions. Dependent on the generated reactant ion species, various ionization pathways are possible, ranging from simple charge transfer to chemical reactions such as proton transfer, ligand switching, hydride ion transfer or ion-molecule adduct formation. In a previous study, by coupling the HiKE-IMS to a mass spectrometer, the occurring positive reactant ions in HiKEIMS in purified air containing 60 ppm $_{v}$ of $\mathrm{H}_{2} \mathrm{O}$ could be identified as $\mathrm{H}^{+}\left(\mathrm{H}_{2} \mathrm{O}\right)_{n}, \mathrm{O}_{2}{ }^{+}\left(\mathrm{H}_{2} \mathrm{O}\right)_{n}$ and $\mathrm{NO}^{+}\left(\mathrm{H}_{2} \mathrm{O}\right)_{n}$ 9 . In this work, the ion-molecule reactions underlying the formation of these reactant ion species are extensively studied in dependence on the reduced electric reaction field strength, the water concentration in the sample gas and the operating pressure. In a parallel study, the formation of negative reactant ions in HiKE-IMS is investigated ${ }^{10}$.

Typically, $\mathrm{H}^{+}\left(\mathrm{H}_{2} \mathrm{O}\right)_{n}$ drives proton transfer and ligand switching reactions ${ }^{5}$. Proton transfer reactions are possible when the proton affinity of the analyte molecule exceeds that of $\left(\mathrm{H}_{2} \mathrm{O}\right)_{n}$. However, the proton affinity of $\left(\mathrm{H}_{2} \mathrm{O}\right)_{n}$ increases with increasing cluster size $n^{11,12}$, which in turn depends on the water concentration, the pressure and the effective ion temperature ${ }^{13-18}$. In contrast, $\mathrm{NO}^{+}\left(\mathrm{H}_{2} \mathrm{O}\right)_{n}$ drives charge transfer ${ }^{19}$, hydride ion transfer ${ }^{20,21,19}$ or adduct formation reactions ${ }^{20,19}$. Analytes with ionization energies below that of $\mathrm{NO}$ react rapidly via charge exchange reactions with $\mathrm{NO}^{+}\left(\mathrm{H}_{2} \mathrm{O}\right)_{n}$, whereas adduct formation with $\mathrm{NO}^{+}$is possible when the ionization energy of the analytes is only slightly lower or higher than that of NO. Reactions of $\mathrm{O}_{2}^{+}\left(\mathrm{H}_{2} \mathrm{O}\right)_{n}$ with organic molecules are dominated by charge transfer reactions. However, due to the high ionization energy of $\mathrm{O}_{2}$, there is a high amount of excess energy on charge transfer that will be deposited in the product ion and may result in ion fragmentation ${ }^{19,20}$.

Thus, to predict the ionization pathways of specific analytes in HiKE-IMS, a detailed knowledge about the reactant ion species generated in HiKE-IMS in dependence on the conditions during ionization is necessary. Hence, the aim of this work is to develop a simple model predicting the ion-molecule reactions in HiKE-IMS, based on thermodynamic and kinetic data. To verify the model, the positive reactant ion population in HiKE-IMS in air is experimentally investigated as a function of the reduced electric field strength in the reaction region, the water concentration in the sample gas and the operating pressure. All of these parameters do not only affect the reactant ion species formed in HiKEIMS, but also their relative abundances and thus the ionization pathways of analytes.

\section{Experimental}

\section{HiKE-IMS}

The HiKE-IMS used in this work is identical to the setup reported previously ${ }^{3}$. A schematic of the HiKEIMS is shown in Figure 1 and the default operating parameters are given in Table 1. The HiKE-IMS consists of a $77 \mathrm{~mm}$ long reaction region and a $306 \mathrm{~mm}$ long drift region. Ions are generated in the reaction region using a corona discharge ionization source before they are separated in the drift region. In both, the reaction and drift region, the reduced electric field strength can be independently increased up to $120 \mathrm{Td}$ by altering the reaction and drift voltage at constant pressure. lons are injected from the reaction region into the drift region through an ion gate consisting of three grids invoking the low-discrimination tristate ion shutter mechanism ${ }^{3}$. The gate opening time is $1 \mu \mathrm{s}$. A fast current amplifier (Femto, DLPCA-200, $400 \mathrm{kHz}, 1 \times 10^{7} \mathrm{~V} / \mathrm{A}$ ) is connected to the Faraday plate detector. Spectra are recorded and averaged using a digitizer with onboard averaging (Keysight, U1082A). The HiKE-IMS resolving power varies from $R=140$ at $120 \mathrm{Td}$ to $R=80$ at $25 \mathrm{Td}$ in the drift region. Drift and sample 
gas are connected to the HiKE-IMS via capillaries with $250 \mu \mathrm{m}$ inner diameter and adjusted lengths to provide gas flow rates of $19 \mathrm{ml}_{\mathrm{s}} / \mathrm{min}$ (milliliter standard per minute, mass flow at reference conditions $20{ }^{\circ} \mathrm{C}$ and $1013.25 \mathrm{hPa}$ ). The drift gas flows through the drift tube and the reaction tube and mixes within the reaction tube with the sample gas. The HiKE-IMS is evacuated via a membrane pump (Pfeiffer Vacuum, MVP 40). The pressure within the HiKE-IMS is monitored with a capacitive pressure gauge (Pfeiffer Vacuum, CMR 362). By adjusting the pumping rate by a throttle valve (Pfeiffer Vacuum, EVN 116), the pressure within the HiKE-IMS can be varied between 14 and 22 mbar. Furthermore, the HiKE-IMS is embedded in a temperature-controlled housing.

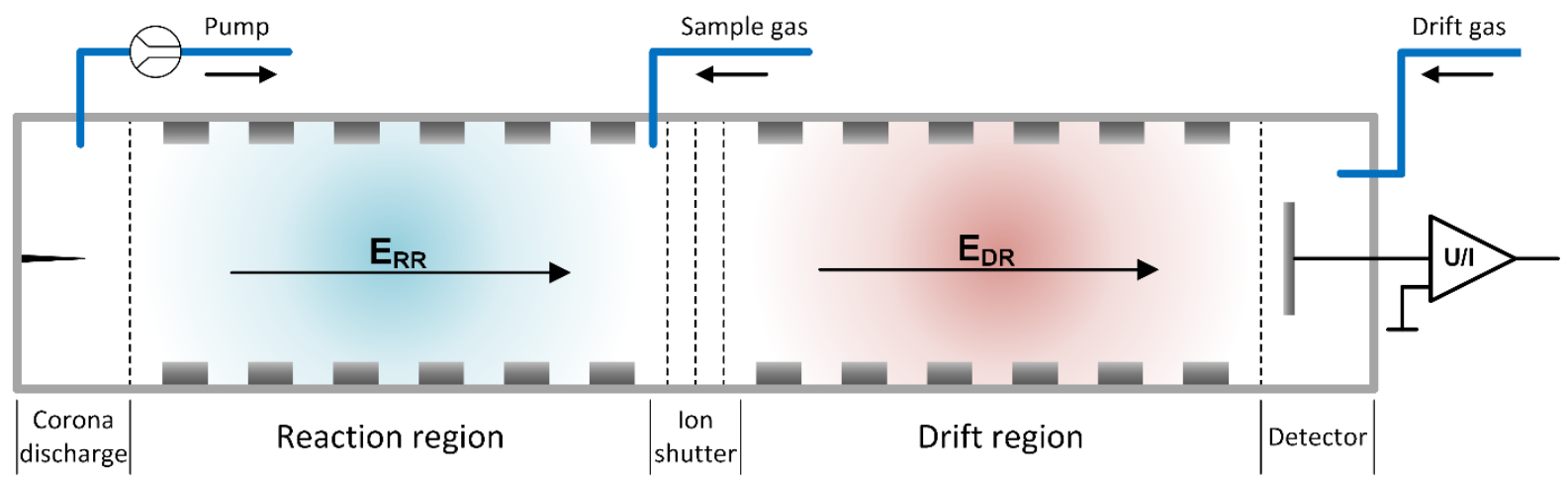

Figure 1: Schematic of the HiKE-IMS

Table 1: HiKE-IMS operating parameters.

${ }^{a} \mathrm{~m} / \mathrm{s} / \mathrm{min}$ : milliliter standard per minute, mass flow at reference conditions $20^{\circ} \mathrm{C}$ and $1013.25 \mathrm{hPa}$

\begin{tabular}{l|l}
\hline Parameter & Value \\
\hline Temperature & $45^{\circ} \mathrm{C}$ \\
Pressure & $14-22 \mathrm{mbar}$ \\
Drift gas flow & $19 \mathrm{ml}_{\mathrm{s}} / \mathrm{min}^{\text {a }}$ \\
Sample gas flow & $19 \mathrm{ml}_{\mathrm{s}} / \mathrm{min}^{\text {a }}$ \\
Drift region length & $306 \mathrm{~mm}$ \\
Reduced drift field & up to $120 \mathrm{Td}$ \\
Reaction region length & $77 \mathrm{~mm}$ \\
Reduced reaction field & up to $120 \mathrm{Td}$ \\
CD voltage & $1250 \mathrm{~V}$ \\
CD current & $3 \mu \mathrm{A}$ \\
Effective CD voltage & $930 \mathrm{~V}$ \\
Injection time & $1 \mu \mathrm{s}$
\end{tabular}

\section{Corona discharge ionization source}

The HiKE-IMS is equipped with a stainless steel corona discharge needle from Agilent (corona needle APCI, G1947-20029) with a needle diameter of $660 \mu \mathrm{m}$. The corona discharge ionization source is operated in reverse flow regime ${ }^{22}$, which essentially means a gas flow from the reaction region towards the corona needle. For all measurements presented in this work, flow rates of $19 \mathrm{ml}_{\mathrm{s}} / \mathrm{min}$ for the drift gas and $19 \mathrm{ml}_{\mathrm{s}} / \mathrm{min}$ for the sample gas have been used. Thus, an overall reverse gas flow of 
$38 \mathrm{ml}_{\mathrm{s}} / \mathrm{min}$ results to flush radicals and neutrals generated by the corona discharge from the reaction region.

A stainless steel grid with $80 \%$ optical transparency serves as counter electrode for the corona discharge needle in a point-to-plane electrode configuration. The gap distance between needle tip and grid is $2 \mathrm{~mm}$. Using an external series resistance of $100 \mathrm{MOhm}$, the applied corona discharge voltage of $1250 \mathrm{~V}$ results in a corona discharge current of $3 \mu \mathrm{A}$ leading to an effective corona discharge voltage of $930 \mathrm{~V}$ between the needle tip and grid electrode.

\section{Gas supply}

Purified air containing less than $1 \mathrm{ppm}_{\mathrm{v}}$ of water is supplied by a zero air generator (JAG, JAGZAG600S) combined with a pressure swing absorber (PureGas, CAS1) in series with an additional moisture trap and an activated carbon filter. The water concentration in the sample and drift gas can be independently varied by mixing the supplied purified air with air that is passed through a water container. The resulting humidity of the sample and drift gas is measured by a dew point sensor (Michell Instruments, Easidew Transmitter).

However, due to diffusion through seals and tubings, the residual water concentration in the HiKE-IMS

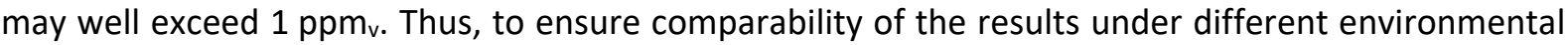
conditions (ambient temperature, pressure and humidity), the lowest water concentration in the sample and drift gas was intentionally increased to $70 \mathrm{ppm}_{\mathrm{v}}$.

\section{Formation of positive reactant ions in HiKE-IMS}

In the last decades, the formation of positive ions using various atmospheric pressure chemical ionization (APCl) sources in air, pure nitrogen, and oxygen has been the subject of intense research. Thus, the underlying ion-molecule reactions resulting in the formation of the observed ions in the HiKEIMS are well known from literature. In particular, at thermal ion-molecule interaction energies, the occurring ion-molecule reactions are well characterized with respect to thermodynamic and kinetic data, enabling an accurate kinetic modelling.

In Figure 2, a simplified reaction scheme is shown summarizing the formation of positive ions in APCI sources in air at thermal ( $300 \mathrm{~K})$ conditions. Typically, the ion formation mechanisms are initiated by the ionization of the main constituents of the sample gas resulting mainly in nitrogen $\mathrm{N}_{2}{ }^{+}$and oxygen $\mathrm{O}_{2}{ }^{+}$radical cations. Additionally, considerable amounts of nitrogen oxide cations $\mathrm{NO}^{+}$and nitrogen dioxide cations $\mathrm{NO}_{2}{ }^{+}$may form. However, the lifetime of the primary ions $\mathrm{N}_{2}{ }^{+}, \mathrm{O}_{2}{ }^{+}, \mathrm{NO}^{+}$, and $\mathrm{NO}_{2}{ }^{+}$is limited, as they react with water via complex reaction cascades to protonated water clusters $\mathrm{H}^{+}\left(\mathrm{H}_{2} \mathrm{O}\right)_{n}$. In the following, relevant ion-molecule reactions are described in detail.

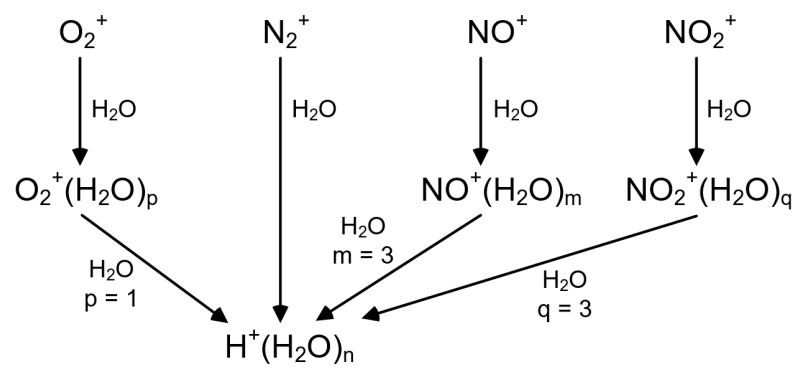

Figure 2: Simplified reaction scheme for the formation of positive ions in APCl sources in air.

In the literature, three different reaction pathways have been proposed to describe the conversion of the primary $\mathrm{N}_{2}{ }^{+}$radical cation to the hydronium ion $\mathrm{H}_{3} \mathrm{O}^{+23-25}$. 
(a) $\mathrm{H}_{3} \mathrm{O}^{+}$is formed through the intermediate $\mathrm{N}_{2} \mathrm{H}^{+}$,

$$
\begin{gathered}
\mathrm{N}_{2}{ }^{+}+\mathrm{H}_{2} \mathrm{O} \rightarrow \mathrm{N}_{2} \mathrm{H}^{+}+\mathrm{OH} \\
\mathrm{N}_{2} \mathrm{H}^{+}+\mathrm{H}_{2} \mathrm{O} \rightarrow \mathrm{H}_{3} \mathrm{O}^{+}+\mathrm{N}_{2}
\end{gathered}
$$

(b) $\mathrm{H}_{3} \mathrm{O}^{+}$is formed through the intermediate $\mathrm{H}_{2} \mathrm{O}^{+}$,

$$
\begin{gathered}
\mathrm{N}_{2}{ }^{+}+\mathrm{H}_{2} \mathrm{O} \rightarrow \mathrm{H}_{2} \mathrm{O}^{+}+\mathrm{N}_{2} \\
\mathrm{H}_{2} \mathrm{O}^{+}+\mathrm{H}_{2} \mathrm{O} \rightarrow \mathrm{H}_{3} \mathrm{O}^{+}+\mathrm{OH}
\end{gathered}
$$

(c) $\mathrm{H}_{3} \mathrm{O}^{+}$is formed through the intermediates $\mathrm{H}_{2} \mathrm{O}^{+}$and $\mathrm{N}_{4}{ }^{+}$.

$$
\begin{aligned}
& \mathrm{N}_{2}^{+}+\mathrm{N}_{2}+\mathrm{M} \leftrightarrow \mathrm{N}_{4}^{+}+\mathrm{M} \\
& \mathrm{N}_{4}^{+}+\mathrm{H}_{2} \mathrm{O} \rightarrow \mathrm{H}_{2} \mathrm{O}^{+}+2 \mathrm{~N}_{2} \\
& \mathrm{H}_{2} \mathrm{O}^{+}+\mathrm{H}_{2} \mathrm{O} \rightarrow \mathrm{H}_{3} \mathrm{O}^{+}+\mathrm{OH}
\end{aligned}
$$

In pure nitrogen and pressures exceeding 1 mbar, the vast majority of $\mathrm{H}_{3} \mathrm{O}^{+}$is generated via reaction channel (c), as the three-body-process (5) is very fast due to the high concentration of neutral molecules $\mathrm{M}^{25}$. Once $\mathrm{H}_{3} \mathrm{O}^{+}$has been generated, the ion forms clusters with further neutral water molecules. The cluster size $\mathrm{n}$ depends on the water content of the sample gas, the pressure and the effective ion temperature ${ }^{26-29}$.

$$
\mathrm{H}_{3} \mathrm{O}^{+}\left(\mathrm{H}_{2} \mathrm{O}\right)_{n-1}+\mathrm{H}_{2} \mathrm{O}+\mathrm{M} \rightleftharpoons \mathrm{H}_{3} \mathrm{O}^{+}\left(\mathrm{H}_{2} \mathrm{O}\right)_{n}+\mathrm{M}
$$

In air, the radical cation $\mathrm{O}_{2}{ }^{+}$is the dominant precursor ion for the formation of protonated water clusters $\mathrm{H}^{+}\left(\mathrm{H}_{2} \mathrm{O}\right)_{n}$, as $\mathrm{N}_{2}{ }^{+}, \mathrm{N}_{4}{ }^{+}$and $\mathrm{H}_{2} \mathrm{O}^{+}$react very fast via direct charge transfer reaction to $\mathrm{O}_{2}^{+}$when colliding with neutral oxygen ${ }^{24,30}$.

$$
\begin{array}{r}
\mathrm{N}_{2}^{+}+\mathrm{O}_{2} \rightarrow \mathrm{O}_{2}^{+}+\mathrm{N}_{2} \\
\mathrm{~N}_{4}^{+}+\mathrm{O}_{2} \rightarrow \mathrm{O}_{2}^{+}+2 \mathrm{~N}_{2} \\
\mathrm{H}_{2} \mathrm{O}^{+}+\mathrm{O}_{2} \rightarrow \mathrm{O}_{2}^{+}+\mathrm{H}_{2} \mathrm{O}
\end{array}
$$

The conversion of the radical cation $\mathrm{O}_{2}{ }^{+}$to protonated water clusters $\mathrm{H}^{+}\left(\mathrm{H}_{2} \mathrm{O}\right)_{n}$ has been investigated in various studies ${ }^{31-39}$. Typically, it is assumed that protonated water clusters $\mathrm{H}^{+}\left(\mathrm{H}_{2} \mathrm{O}\right)_{n}$ are generated from the oxygen-water cluster $\mathrm{O}_{2}^{+}\left(\mathrm{H}_{2} \mathrm{O}\right)$. In the literature, three different reaction pathways have been proposed to describe the formation of $\mathrm{O}_{2}{ }^{+}\left(\mathrm{H}_{2} \mathrm{O}\right)$ :

(a) direct clustering,

$$
\mathrm{O}_{2}^{+}+\mathrm{H}_{2} \mathrm{O}+\mathrm{M} \rightleftharpoons \mathrm{O}_{2}^{+}\left(\mathrm{H}_{2} \mathrm{O}\right)+\mathrm{M}
$$

(b) via the intermediate $\mathrm{O}_{4}{ }^{+}$,

$$
\begin{gathered}
\mathrm{O}_{2}{ }^{+}+\mathrm{O}_{2}+\mathrm{M} \rightleftharpoons \mathrm{O}_{4}{ }^{+}+M \\
\mathrm{O}_{4}{ }^{+}+\mathrm{H}_{2} \mathrm{O} \rightarrow \mathrm{O}_{2}{ }^{+}\left(\mathrm{H}_{2} \mathrm{O}\right)+\mathrm{O}_{2}
\end{gathered}
$$

(c) via the intermediate $\mathrm{O}_{2}{ }^{+} \mathrm{N}_{2}$.

$$
\begin{gathered}
\mathrm{O}_{2}{ }^{+}+\mathrm{N}_{2}+\mathrm{M} \rightleftharpoons \mathrm{O}_{2}{ }^{+}\left(\mathrm{N}_{2}\right)+M \\
\mathrm{O}_{2}{ }^{+}\left(\mathrm{N}_{2}\right)+\mathrm{H}_{2} \mathrm{O} \rightarrow \mathrm{O}_{2}{ }^{+}\left(\mathrm{H}_{2} \mathrm{O}\right)+\mathrm{N}_{2}
\end{gathered}
$$


At a subsequent collision with water, $\mathrm{O}_{2}{ }^{+}\left(\mathrm{H}_{2} \mathrm{O}\right)$ reacts with $\mathrm{H}_{2} \mathrm{O}$ to form directly $\mathrm{H}_{3} \mathrm{O}^{+}\left(\mathrm{H}_{2} \mathrm{O}\right)_{n}$ or via the intermediates $\mathrm{H}_{3} \mathrm{O}^{+} \mathrm{OH}$ or $\mathrm{O}_{2}^{+}\left(\mathrm{H}_{2} \mathrm{O}\right)_{2}$.

$$
\begin{gathered}
\mathrm{O}_{2}{ }^{+}\left(\mathrm{H}_{2} \mathrm{O}\right)+\mathrm{H}_{2} \mathrm{O} \rightarrow \mathrm{H}_{3} \mathrm{O}^{+}+\mathrm{OH}+\mathrm{O}_{2} \\
\mathrm{O}_{2}{ }^{+}\left(\mathrm{H}_{2} \mathrm{O}\right)+\mathrm{H}_{2} \mathrm{O} \rightarrow \mathrm{H}_{3} \mathrm{O}^{+} \mathrm{OH}+\mathrm{O}_{2} \\
\mathrm{H}_{3} \mathrm{O}^{+} \mathrm{OH}+\mathrm{H}_{2} \mathrm{O} \rightarrow \mathrm{H}_{3} \mathrm{O}^{+}\left(\mathrm{H}_{2} \mathrm{O}\right)+\mathrm{OH} \\
\mathrm{O}^{+}{ }^{+}\left(\mathrm{H}_{2} \mathrm{O}\right)+\mathrm{H}_{2} \mathrm{O} \rightarrow \mathrm{O}_{2}{ }^{+}\left(\mathrm{H}_{2} \mathrm{O}\right)_{2} \\
\mathrm{O}_{2}{ }^{+}\left(\mathrm{H}_{2} \mathrm{O}\right)_{2}+\mathrm{H}_{2} \mathrm{O} \rightarrow\left(\mathrm{H}_{2} \mathrm{O}\right)_{3}{ }^{+}+\mathrm{O}_{2} \\
\left(\mathrm{H}_{2} \mathrm{O}\right)_{3}{ }^{+}+\mathrm{H}_{2} \mathrm{O} \rightarrow \mathrm{H}_{3} \mathrm{O}^{+}\left(\mathrm{H}_{2} \mathrm{O}\right)_{2}+\mathrm{OH}
\end{gathered}
$$

Comparable to $\mathrm{O}_{2}{ }^{+}$, the primary ions $\mathrm{NO}^{+}$and $\mathrm{NO}_{2}{ }^{+}$also form clusters with water molecules. In contrast to $\mathrm{O}_{2}{ }^{+}$, these clusters are stable for cluster sizes $\mathrm{m}, \mathrm{q} \leq 3^{40,41}$.

$$
\begin{aligned}
& \mathrm{NO}^{+}\left(\mathrm{H}_{2} \mathrm{O}\right)_{m-1}+\mathrm{H}_{2} \mathrm{O}+\mathrm{M} \rightleftharpoons \mathrm{NO}^{+}\left(\mathrm{H}_{2} \mathrm{O}\right)_{m}+\mathrm{M} \\
& \mathrm{NO}_{2}{ }^{+}\left(\mathrm{H}_{2} \mathrm{O}\right)_{q-1}+\mathrm{H}_{2} \mathrm{O}+\mathrm{M} \rightleftharpoons \mathrm{NO}_{2}^{+}\left(\mathrm{H}_{2} \mathrm{O}\right)_{q}+\mathrm{M}
\end{aligned}
$$

However, at a subsequent collision with $\mathrm{H}_{2} \mathrm{O}$, the ions $\mathrm{NO}^{+}\left(\mathrm{H}_{2} \mathrm{O}\right)_{3}$ and $\mathrm{NO}_{2}{ }^{+}\left(\mathrm{H}_{2} \mathrm{O}\right)_{3}$ are also converted to protonated water clusters $\mathrm{H}^{+}\left(\mathrm{H}_{2} \mathrm{O}\right)_{3}$ accompanied by the release of either nitrous acid $\left(\mathrm{HNO}_{2}\right)$ or nitric acid $\left(\mathrm{HNO}_{3}\right)^{41,42}$.

$$
\begin{aligned}
& \mathrm{NO}^{+}\left(\mathrm{H}_{2} \mathrm{O}\right)_{3}+\mathrm{H}_{2} \mathrm{O} \rightarrow \mathrm{H}^{+}\left(\mathrm{H}_{2} \mathrm{O}\right)_{3}+\mathrm{HNO}_{2} \\
& \mathrm{NO}_{2}{ }^{+}\left(\mathrm{H}_{2} \mathrm{O}\right)_{3}+\mathrm{H}_{2} \mathrm{O} \rightarrow \mathrm{H}^{+}\left(\mathrm{H}_{2} \mathrm{O}\right)_{3}+\mathrm{HNO}_{3}
\end{aligned}
$$

In summary, in the thermodynamic equilibrium at thermal conditions $(\sim 300 \mathrm{~K})$, the protonated water clusters $\mathrm{H}^{+}\left(\mathrm{H}_{2} \mathrm{O}\right)_{n}$ are the predominant positive ion species formed in air even at low background water concentrations of just 1 ppm $_{\mathrm{v}}$. However, due to the operation at reduced pressure accompanied by short reaction times, this thermodynamic equilibrium may not be reached in the HiKE-IMS. Depending on the reduced electric field strength, the ions residence time in the reaction region of the HiKE-IMS is between $60 \mu \mathrm{s}(120 \mathrm{Td})$ and $500 \mu \mathrm{s}(20 \mathrm{Td})$. Thus, to predict the ion population formed in the reaction region of the HiKE-IMS, the kinetics of the reactions discussed above are highly relevant. Furthermore, due to the operation at high reduced electric field strengths, the ion-molecule interaction energies in the HiKE-IMS significantly exceed thermal ion-molecule interaction energies. As elevated collisional ion energies favor cluster dissociation processes, particularly the cluster formation and dissociation equilibria (5), (7), (11), (12), (14), (22) and (23) are strongly affected by the reduced electric field strength.

In order to evaluate the time-dependent changes of the concentration of each ion species in the reaction region of the HiKE-IMS, reactions (1) - (25) and their corresponding reaction rate constants can be expressed by a system of ordinary differential equations. Since the neutral reaction partners are present in vast excess, all reactions are considered to be pseudo-first order with respect to the ionic species. The numerical solution of the resulting differential equation system provides the concentration of each ionic species as a function of time. In this work, the differential equation system is solved using the MATLAB function "ode45" which implements a Runge-Kutta $(4,5)$ integration scheme. 
The field dependence of the reaction system is estimated using the temperature dependence of the equilibrium constants of the equilibria reactions (5), (7), (11), (12), (14), (22) and (23). According to Wannier, the energy of ions in an electric field can be expressed in terms of an effective ion temperature $T_{\text {eff }}{ }^{4,43}$.

$$
T_{e f f}=T+\frac{1}{3} \frac{M}{k_{b}} \cdot v_{d}^{2}=T+\frac{1}{3} \frac{M N_{0}^{2}}{k_{b}} K_{0}^{2}\left(\frac{E}{N}\right)^{2}
$$

Here, $k_{b}$ is the Boltzmann constant and $N_{0}$ the Loschmidt constant (number density at $273.15 \mathrm{~K}$ and 1013 mbar). The effective ion temperature $T_{\text {eff }}$ depends on the absolute temperature $T$, the mass $M$ of the neutral gas molecule and the drift velocity $v_{d}$ of the ions which in turn depends on the reduced ion mobility $K_{0}$ and the reduced electric field strength $(E / N)$. The reduced ion mobility $K_{0}$ represents the ion mobility at $273.15 \mathrm{~K}$ and 1013 mbar. Considering a simple clustering reaction of an analyte $\mathrm{A}^{+}$, a clustering agent $\mathrm{S}$ and the third body $\mathrm{M}$,

$$
A^{+}+S+M \rightleftharpoons A S^{+}+M
$$

the equilibrium constant $K_{\text {equi }}$ is calculated by the ratio of the forward rate constant $k_{\text {for }}$ and the backward rate constant $k_{\text {back. }}$.

$$
K_{\text {equi }}=\frac{k_{\text {for }}}{k_{\text {back }}}
$$

A connection between the equilibrium constant $K_{\text {equi }}$ and the temperature $T$ is given by the van't Hoff equation (29) ${ }^{44}$

$$
\frac{d \ln \left(K_{e q u i}\right)}{d T}=\frac{\Delta_{r} H^{0}(T)}{R T^{2}}
$$

with the molar standard reaction enthalpy $\Delta_{r} H^{0}$ as function of $T$ and the universal gas constant $R$. The assumption of $\Delta_{r} H^{0}(T)=$ const. in a temperature interval allows simple integration to calculate the equilibrium constant $K_{\text {equi,2 }}$ at a temperature $T_{2}$ from a known equilibrium constant $K_{\text {equi,1 }}$ at temperature $T_{1}$ :

$$
\ln \left(\frac{K_{\text {equi, } 2}}{K_{\text {equi, }}}\right)=-\frac{\Delta_{r} H^{0}}{R}\left(\frac{1}{T_{2}}-\frac{1}{T_{1}}\right)
$$

It follows for Kequi,2:

$$
K_{e q u i, 2}=K_{e q u i, 1} \cdot e^{\left(-\frac{\Delta_{r} H^{0}}{R}\left(\frac{1}{T_{2}}-\frac{1}{T_{1}}\right)\right)}
$$

$K_{\text {equi, } 1}$ can be calculated from the Gibbs enthalpy of the reaction $\Delta_{r} G^{0}$ or the molar standard reaction enthalpy $\Delta_{r} H^{0}$ as well as the molar standard reaction entropy $\Delta_{r} S^{0}$ at standard temperature (298.15 K) according to equation 32.

$$
\ln \left(K_{\text {equi,1 }}\right)=-\frac{\Delta_{r} G^{0}(T)}{R T}=-\frac{\Delta_{r} H^{0}(T)-T \cdot \Delta_{r} S^{0}(T)}{R T}
$$

Assuming the forward rate constant $k_{\text {for }}$ to be independent on the electric field, equation 33 finally yields the backward reaction rate constant $k_{\text {back }}$ in dependence on the effective ion temperature $T_{\text {eff: }}$ :

$$
k_{\text {back }}\left(T_{\text {eff }}\right)=\frac{k_{\text {for }}}{K_{\text {equi }, 2}\left(T_{\text {eff }}\right)}=\frac{k_{\text {for }}}{K_{\text {equi }, 1} \cdot e^{\left(-\frac{\Delta_{r} H^{0}}{R}\left(\frac{1}{T_{\text {eff }}}-\frac{1}{T_{1}}\right)\right)}}
$$


Thus, the forward rate constant $k_{\text {for }}$, the molar standard reaction enthalpy $\Delta_{r} H^{0}$ and the molar standard reaction entropy $\Delta_{r} S^{0}$ at standard temperature $(298.15 \mathrm{~K})$ are required to model the fielddependence of the reaction system. Additionally, the reduced ion mobilities $K_{0}$ are needed to calculate the effective ion temperature. Fortunately, particularly at thermal ion-molecule interaction energies, comprehensive thermodynamic and kinetic data are available from the literature. Furthermore, as implemented in the statistical diffusion simulation (SDS) user program for SIMION, the reduced ion mobilities $K_{0}$ can be estimated from the mass of the ions. In this estimation, the diameter $d_{i o n}$ of the ion in $\mathrm{nm}$ is calculated by equation 34 using the mass $m_{i o n}$ of the ion in the unified atomic mass unit $u$.

$$
d_{\text {ion }}=0.12 \cdot \sqrt[3]{m_{\text {ion }}}
$$

The reduced ion mobility $K_{0}$ in $\mathrm{cm}^{2} / \mathrm{Vs}$ results from equation 35 .

$$
K_{0}=1 \cdot 10^{-5} \cdot 10^{4.91-1.45\left(\log _{10}\left(d_{\text {ion }}\right)\right)-0.28\left(\log _{10}\left(d_{\text {ion }}\right)\right)^{2}+0.07\left(\log _{10}\left(d_{\text {ion }}\right)\right)^{3}}
$$

A detailed derivation of equations 34 and 35 is described in ${ }^{45}$. The only data that are not available from the literature are the molar standard reaction entropies $\Delta_{r} S^{0}$ at standard temperature for the hydration of $\mathrm{O}_{2}{ }^{+}$(reaction 11 in Table 2) and $\mathrm{NO}^{+}\left(\mathrm{H}_{2} \mathrm{O}\right)_{2}$ (reaction 22c in Table 2). In accordance with the experimental results from this work, these values are assumed to be $-18 \mathrm{cal} \mathrm{mol}^{-1} \mathrm{~K}^{-1}$ and $-30 \mathrm{cal}$ $\mathrm{mol}^{-1} \mathrm{~K}^{-1}$, respectively.

In Table 2, the thermodynamic and kinetic data used in this work are summarized. Based on these data, the time-dependent ion abundances in Figure 3 have been calculated for three different reduced electric field strengths at a temperature of $45^{\circ} \mathrm{C}$, a pressure of $14.3 \mathrm{mbar}$ and a background water concentration of $70 \mathrm{ppm}_{\mathrm{v}}$. According to the neutral gas composition of air and the experimental results, we assume a primary ion distribution of $10 \% \mathrm{NO}^{+}, 70 \% \mathrm{~N}_{2}{ }^{+}$and $20 \mathrm{O} \mathrm{O}_{2}{ }^{+}$. However, due to the high concentration of oxygen in air, the primary ions $\mathrm{N}_{2}{ }^{+}$react to $\mathrm{O}_{2}{ }^{+}$within nanoseconds. Furthermore, as shown in Figure 3, at a reduced electric field strength of $20 \mathrm{Td}$, it takes about $100 \mu$ s to convert these $\mathrm{O}_{2}{ }^{+}$ions to protonated water clusters $\mathrm{H}^{+}\left(\mathrm{H}_{2} \mathrm{O}\right)_{\mathrm{n}}$. In contrast, the $\mathrm{NO}^{+}$bound water cluster system $\mathrm{NO}^{+}\left(\mathrm{H}_{2} \mathrm{O}\right)_{m}$ does not reach an equilibrium even after $1 \mathrm{~ms}$. With increasing reduced electric field strength, not only the cluster sizes $n$ and $m$ of $\mathrm{H}^{+}\left(\mathrm{H}_{2} \mathrm{O}\right)_{n}$ and $\mathrm{NO}^{+}\left(\mathrm{H}_{2} \mathrm{O}\right)_{m}$ in the thermodynamic equilibrium decrease, but also the lifetime of $\mathrm{O}_{2}{ }^{+}$increases. At a reduced electric field strength of $60 \mathrm{Td}$, the conversion of $\mathrm{O}_{2}{ }^{+}$to protonated water clusters $\mathrm{H}^{+}\left(\mathrm{H}_{2} \mathrm{O}\right)_{n}$ takes about $600 \mu \mathrm{s}$, as the conversion of $\mathrm{O}_{2}{ }^{+}$via the intermediate cluster $\mathrm{O}_{2}^{+}\left(\mathrm{H}_{2} \mathrm{O}\right)$ to protonated water clusters $\mathrm{H}^{+}\left(\mathrm{H}_{2} \mathrm{O}\right)_{n}$ is increasingly inhibited at elevated field strength due to the collision induced dissociation of $\mathrm{O}_{2}{ }^{+}\left(\mathrm{H}_{2} \mathrm{O}\right)$. At a reduced electric field strength of $100 \mathrm{Td}$, the conversion of $\mathrm{O}_{2}{ }^{+}$to $\mathrm{H}^{+}\left(\mathrm{H}_{2} \mathrm{O}\right)_{n}$ is completely inhibited. 


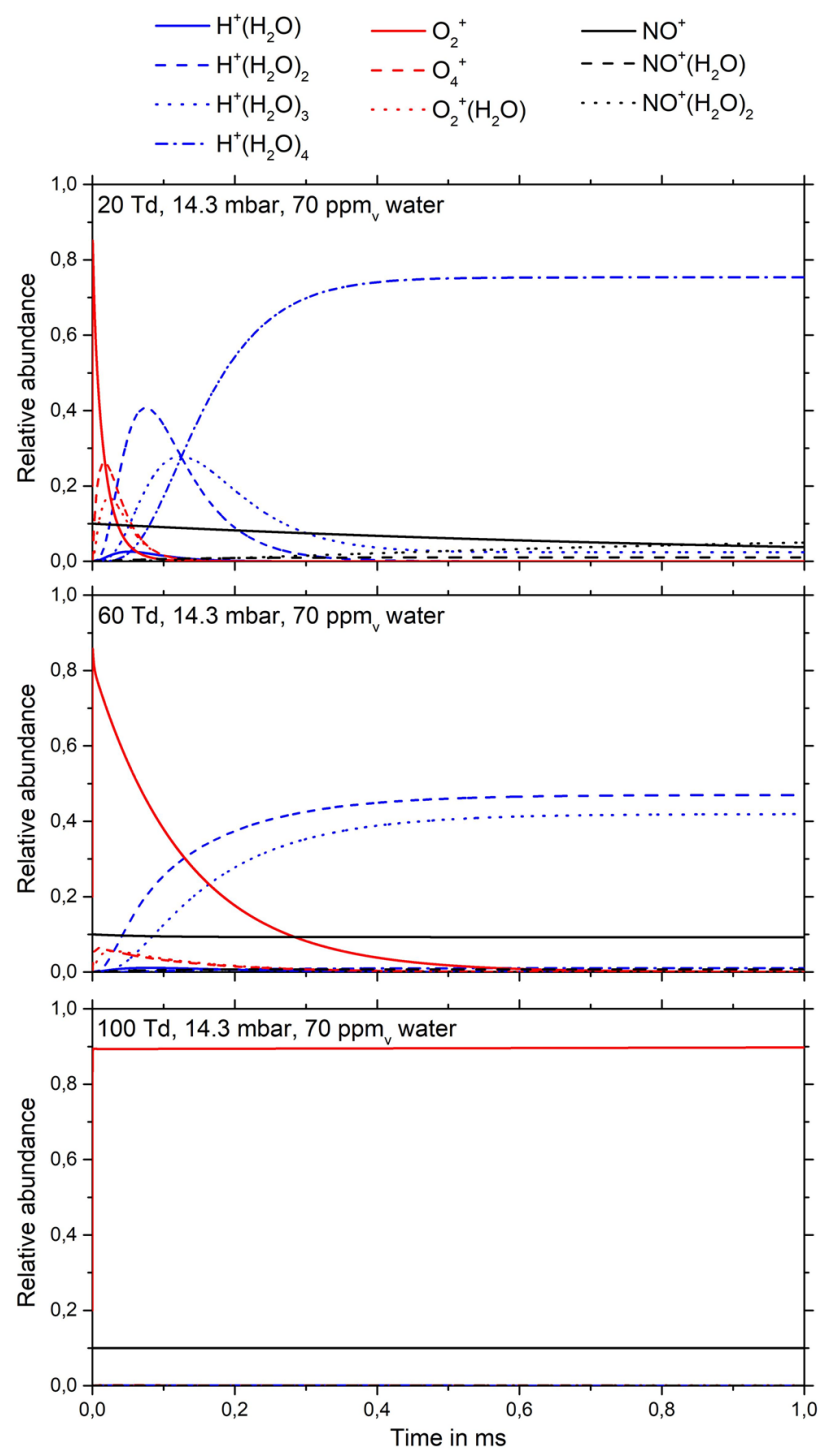

Figure 3: Time-dependent ion abundances in air for three different reduced electric field strengths at a pressure of $14.3 \mathrm{mbar}$, a temperature of $45^{\circ} \mathrm{C}$ and a background water concentration of $70 p p p m_{\mathrm{v}}$. The values are calculated based on the kinetic data listed in Table 2. The initial ion distribution is: $70 \% \mathrm{~N}_{2}^{+}, 20 \% \mathrm{O}_{2}^{+}$and $10 \% \mathrm{NO}^{+}$.

Additionally to the reduced electric field strength, the results of the kinetic model demonstrate the dependence of the ion formation processes in the HiKE-IMS on the background water concentration and the operating pressure, as shown in Figure 4. At the background water concentration of $500 \mathrm{ppm}_{\mathrm{v}}$, equilibrium (11) is shifted to $\mathrm{O}_{2}^{+}\left(\mathrm{H}_{2} \mathrm{O}\right)$ clusters leading to a higher conversion rate of $\mathrm{O}_{2}^{+}$to protonated water clusters even at the high reduced electric field strength of $100 \mathrm{Td}$. A similar effect is observed when increasing the operating pressure from $14.3 \mathrm{mbar}$ to $25.3 \mathrm{mbar}$, as the rate of the three-body cluster association reactions grows faster than the rate of the two-body cluster dissociation reactions. 

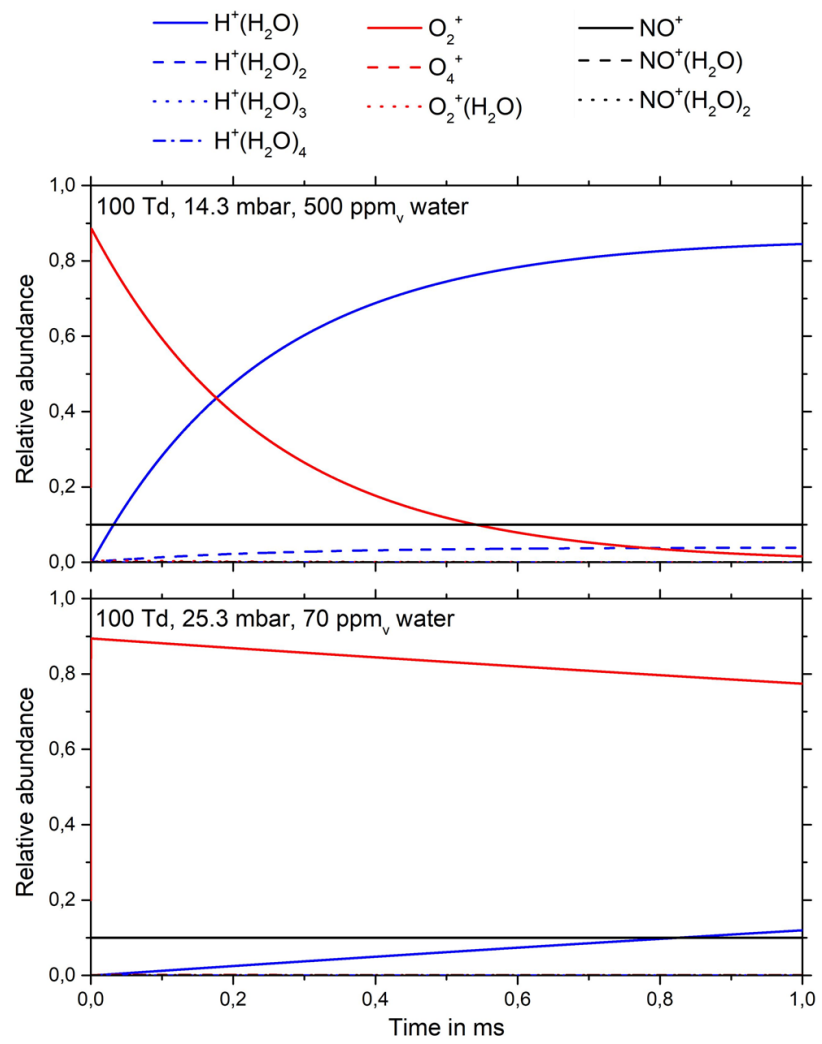

Figure 4: Time-dependent ion abundances in air at a reduced electric field strength of $100 \mathrm{Td}$ and a temperature of $45^{\circ} \mathrm{C}$. The values are calculated based on the kinetic data listed in Table 2. The initial ion distribution is: $70 \% \mathrm{~N}_{2}^{+}, 20 \% \mathrm{O}_{2}^{+}$and $10 \%$ $\mathrm{NO}^{+}$. Upper panel: Background water concentration: 500 ppm $_{v}$, Pressure: 14.3 mbar. Lower panel: Background water concentration: $70 \mathrm{ppm}_{\mathrm{v}}$, Pressure: 25.3 mbar. In comparison to the lowest panel of Figure 3, in the upper panel of this figure, the water concentration is varied and in the lower panel of this figure, the operating pressure is varied.

In summary, the ion formation processes in the HiKE-IMS are strongly defined by the kinetics of the cluster association and dissociation reactions. In particular, the effective ion temperature, the background water concentration as well as the operating pressure affect the rates of the cluster association and dissociation reactions and thus the equilibrium state. In the following section, these dependencies are experimentally investigated.

Table 2: Thermodynamic and kinetic data used in this work to model the positive reactant ion formation mechanisms in the HiKE-IMS. The listed data are determined at $\sim 300 \mathrm{~K}$. The stated reduced ion mobilities $\mathrm{K}_{0}$ are estimated from the mass of the ions according to equations (34) and (35). The field-dependence of the reduced ion mobility is neglected.

\begin{tabular}{|c|c|c|c|c|c|}
\hline & Reaction & $\begin{array}{l}\text { Forward rate constant } \\
\text { in } \frac{\mathrm{cm}^{3}}{\mathrm{~s}} \text { or } \frac{\mathrm{cm}^{6}}{\mathrm{~s}}\end{array}$ & $\begin{array}{l}\Delta_{R} H \text { in } \\
\mathrm{kcal} \mathrm{mol}^{-1}\end{array}$ & $\begin{array}{l}\Delta_{R} S \text { in } \\
\text { cal mol}^{-1} \mathrm{~K}^{-1}\end{array}$ & $\begin{array}{l}\mathrm{K}_{0} \text { of product } \\
\text { ion in } \mathrm{cm}^{2} / \mathrm{Vs}\end{array}$ \\
\hline 1 & $\begin{array}{c}\mathrm{N}_{2}^{+}+\mathrm{H}_{2} \mathrm{O} \rightarrow \\
\mathrm{N}_{2} \mathrm{H}^{+}+\mathrm{OH}\end{array}$ & $9.5 \cdot 10^{-1024}$ & & & \\
\hline 2 & $\begin{array}{c}\mathrm{N}_{2} \mathrm{H}^{+}+\mathrm{H}_{2} \mathrm{O} \rightarrow \\
\mathrm{H}_{3} \mathrm{O}^{+}+\mathrm{N}_{2}\end{array}$ & $2.9 \cdot 10^{-924}$ & & & \\
\hline 3 & $\begin{array}{c}\mathrm{N}_{2}^{+}+\mathrm{H}_{2} \mathrm{O} \rightarrow \\
\mathrm{H}_{2} \mathrm{O}^{+}+\mathrm{N}_{2}\end{array}$ & $1 \cdot 10^{-925}$ & & & \\
\hline 4 & $\begin{array}{c}\mathrm{H}_{2} \mathrm{O}^{+}+\mathrm{H}_{2} \mathrm{O} \rightarrow \\
\mathrm{H}_{3} \mathrm{O}^{+}+\mathrm{OH}\end{array}$ & $1.8 \cdot 10^{-925}$ & & & \\
\hline
\end{tabular}




\begin{tabular}{|c|c|c|c|c|c|}
\hline 5 & $\begin{array}{c}N_{2}^{+}+N_{2}+M \rightleftharpoons \\
N_{4}^{+}+M\end{array}$ & $8 \cdot 10^{-2925}$ & $-25.8^{46}$ & $-21.0^{46}$ & 2.33 \\
\hline 6 & $\begin{array}{l}\mathrm{N}_{4}^{+}+\mathrm{H}_{2} \mathrm{O} \rightarrow \\
\mathrm{H}_{2} \mathrm{O}^{+}+2 \mathrm{~N}_{2}\end{array}$ & $1.9 \cdot 10^{-925}$ & & & \\
\hline $7 a$ & $\begin{array}{c}\mathrm{H}_{3} \mathrm{O}^{+}+\mathrm{H}_{2} \mathrm{O}+\mathrm{M} \rightleftharpoons \\
\mathrm{H}_{3} \mathrm{O}^{+}\left(\mathrm{H}_{2} \mathrm{O}\right)+M\end{array}$ & $3.4 \cdot 10^{-2725}$ & $-31.6^{28}$ & $-24.3^{28}$ & 2.76 \\
\hline $7 b$ & $\begin{array}{c}\mathrm{H}_{3} \mathrm{O}^{+}\left(\mathrm{H}_{2} \mathrm{O}\right)+\mathrm{H}_{2} \mathrm{O}+\mathrm{M} \rightleftharpoons \\
\mathrm{H}_{3} \mathrm{O}^{+}\left(\mathrm{H}_{2} \mathrm{O}\right)_{2}+M\end{array}$ & $2.3 \cdot 10^{-2725}$ & $-19.5^{28}$ & $-21.7^{28}$ & 2.35 \\
\hline $7 c$ & $\begin{array}{c}\mathrm{H}_{3} \mathrm{O}^{+}\left(\mathrm{H}_{2} \mathrm{O}\right)_{2}+\mathrm{H}_{2} \mathrm{O}+\mathrm{M} \rightleftharpoons \\
\mathrm{H}_{3} \mathrm{O}^{+}\left(\mathrm{H}_{2} \mathrm{O}\right)_{3}+M\end{array}$ & $2.4 \cdot 10^{-27} 25$ & $-17.9^{28}$ & $-28.4^{28}$ & 2.09 \\
\hline $7 d$ & $\begin{array}{c}\mathrm{H}_{3} \mathrm{O}^{+}\left(\mathrm{H}_{2} \mathrm{O}\right)_{3}+\mathrm{H}_{2} \mathrm{O}+\mathrm{M} \rightleftharpoons \\
\mathrm{H}_{3} \mathrm{O}^{+}\left(\mathrm{H}_{2} \mathrm{O}\right)_{4}+M\end{array}$ & $0.9 \cdot 10^{-27} 33$ & $-12.7^{28}$ & $-23.4^{28}$ & 1.90 \\
\hline 8 & $\begin{array}{c}\mathrm{N}_{2}^{+}+\mathrm{O}_{2} \rightarrow \\
\mathrm{O}_{2}^{+}+\mathrm{N}_{2}\end{array}$ & $4.9 \cdot 10^{-1024}$ & & & \\
\hline 9 & $\begin{array}{l}\mathrm{N}_{4}^{+}+\mathrm{O}_{2} \rightarrow \\
\mathrm{O}_{2}^{+}+2 \mathrm{~N}_{2}\end{array}$ & $1 \cdot 10^{-1024}$ & & & \\
\hline 10 & $\begin{array}{c}\mathrm{H}_{2} \mathrm{O}^{+}+\mathrm{O}_{2} \rightarrow \\
\mathrm{O}_{2}^{+}+\mathrm{H}_{2} \mathrm{O}\end{array}$ & $2 \cdot 10^{-10} 30$ & & & \\
\hline 11 & $\begin{array}{c}\mathrm{O}_{2}^{+}+\mathrm{H}_{2} \mathrm{O}+\mathrm{M} \rightleftharpoons \\
\mathrm{O}_{2}^{+}\left(\mathrm{H}_{2} \mathrm{O}\right)+M\end{array}$ & $2.6 \cdot 10^{-2836}$ & $-18.5^{47}$ & -18.0 & 2.44 \\
\hline 12 & $\begin{array}{c}O_{2}^{+}+O_{2}+M \rightleftharpoons \\
O_{4}^{+}+M\end{array}$ & $2.5 \cdot 10^{-30} 39$ & $-10.8^{34}$ & $-25.0^{34}$ & 2.20 \\
\hline 13 & $\begin{array}{c}\mathrm{O}_{4}^{+}+\mathrm{H}_{2} \mathrm{O} \rightarrow \\
\mathrm{O}_{2}^{+}\left(\mathrm{H}_{2} \mathrm{O}\right)+\mathrm{O}_{2}\end{array}$ & $2.2 \cdot 10^{-9} 48$ & & & \\
\hline 14 & $\begin{array}{l}\mathrm{O}_{2}^{+}+N_{2}+M \rightleftharpoons \\
O_{2}^{+}\left(N_{2}\right)+M\end{array}$ & $8 \cdot 10^{-3148}$ & $-5.0^{46}$ & $-17.4^{46}$ & 2.26 \\
\hline 15 & $\begin{array}{c}\mathrm{O}_{2}^{+}\left(\mathrm{N}_{2}\right)+\mathrm{H}_{2} \mathrm{O} \rightarrow \\
\mathrm{O}_{2}{ }^{+}\left(\mathrm{H}_{2} \mathrm{O}\right)+\mathrm{N}_{2}\end{array}$ & $4 \cdot 10^{-9} 48$ & & & \\
\hline 16 & $\begin{array}{c}\mathrm{O}_{2}{ }^{+}\left(\mathrm{H}_{2} \mathrm{O}\right)+\mathrm{H}_{2} \mathrm{O} \rightarrow \\
\mathrm{H}_{3} \mathrm{O}^{+}+\mathrm{OH}+\mathrm{O}_{2}\end{array}$ & $3 \cdot 10^{-1048}$ & & & \\
\hline 17 & $\begin{array}{c}\mathrm{O}_{2}^{+}\left(\mathrm{H}_{2} \mathrm{O}\right)+\mathrm{H}_{2} \mathrm{O} \rightarrow \\
\mathrm{H}_{3} \mathrm{O}^{+} \mathrm{OH}+\mathrm{O}_{2}\end{array}$ & $1.9 \cdot 10^{-948}$ & & & \\
\hline 18 & $\begin{array}{c}\mathrm{H}_{3} \mathrm{O}^{+} \mathrm{OH}+\mathrm{H}_{2} \mathrm{O} \rightarrow \\
\mathrm{H}_{3} \mathrm{O}^{+}\left(\mathrm{H}_{2} \mathrm{O}\right)+\mathrm{OH}\end{array}$ & $3.2 \cdot 10^{-9} 48$ & & & \\
\hline 19 & $\begin{array}{c}\mathrm{O}_{2}{ }^{+}\left(\mathrm{H}_{2} \mathrm{O}\right)+\mathrm{H}_{2} \mathrm{O} \rightarrow \\
\mathrm{O}_{2}{ }^{+}\left(\mathrm{H}_{2} \mathrm{O}\right)_{2}\end{array}$ & $1.2 \cdot 10^{-936}$ & & & \\
\hline 20 & $\begin{array}{c}\mathrm{O}_{2}^{+}\left(\mathrm{H}_{2} \mathrm{O}\right)_{2}+\mathrm{H}_{2} \mathrm{O} \rightarrow \\
\left(\mathrm{H}_{2} \mathrm{O}\right)_{3}{ }^{+}+\mathrm{O}_{2}\end{array}$ & $1.8 \cdot 10^{-936}$ & & & \\
\hline
\end{tabular}




\begin{tabular}{|c|c|c|c|c|c|}
\hline 21 & $\begin{array}{c}\left(\mathrm{H}_{2} \mathrm{O}\right)_{3}^{+}+\mathrm{H}_{2} \mathrm{O} \rightarrow \\
\mathrm{H}_{3} \mathrm{O}^{+}\left(\mathrm{H}_{2} \mathrm{O}\right)_{2}+\mathrm{OH}\end{array}$ & $2.1 \cdot 10^{-9} 36$ & & & \\
\hline $22 a$ & $\begin{array}{c}N O^{+}+H_{2} O+M \rightleftharpoons \\
N O^{+}\left(H_{2} O\right)+M\end{array}$ & $13 \cdot 10^{-29} 40$ & $-18.5^{42}$ & $-23.0^{42}$ & 2.48 \\
\hline $22 \mathrm{~b}$ & $\begin{array}{l}\mathrm{NO}^{+}\left(\mathrm{H}_{2} \mathrm{O}\right)+\mathrm{H}_{2} \mathrm{O}+\mathrm{M} \rightleftharpoons \\
\mathrm{NO}^{+}\left(\mathrm{H}_{2} \mathrm{O}\right)_{2}+M\end{array}$ & $11 \cdot 10^{-28} 40$ & $-16.1^{42}$ & $-25.5^{42}$ & 2.18 \\
\hline $22 c$ & $\begin{array}{c}\mathrm{NO}^{+}\left(\mathrm{H}_{2} \mathrm{O}\right)_{2}+\mathrm{H}_{2} \mathrm{O}+\mathrm{M} \rightleftharpoons \\
\mathrm{NO}^{+}\left(\mathrm{H}_{2} \mathrm{O}\right)_{3}+M\end{array}$ & $13 \cdot 10^{-28} 40$ & $-13.5^{42}$ & -30.0 & 1.97 \\
\hline 24 & $\begin{array}{c}\mathrm{NO}^{+}\left(\mathrm{H}_{2} \mathrm{O}\right)_{3}+\mathrm{H}_{2} \mathrm{O} \rightarrow \\
\mathrm{H}^{+}\left(\mathrm{H}_{2} \mathrm{O}\right)_{3}+\mathrm{HNO}_{2}\end{array}$ & $7 \cdot 10^{-1140}$ & & & \\
\hline
\end{tabular}

\section{Results and discussion}

In order to experimentally investigate the reactant ion formation mechanisms in the reaction region of the HiKE-IMS, it is important to avoid any reactions in the drift region altering the ion population. Thus, in the presented measurements, the reduced electric field strength in the drift region is set to values exceeding $100 \mathrm{Td}$ and the water concentration in the drift gas is kept constant at $70 \mathrm{ppm}_{\mathrm{v}}$. Under these conditions, further conversion of $\mathrm{O}_{2}{ }^{+}$or $\mathrm{NO}^{+}$to $\mathrm{H}^{+}\left(\mathrm{H}_{2} \mathrm{O}\right)_{n}$ should not occur, as the cluster formation should be completely inhibited in the drift region. To identify the ion species in the HiKEIMS spectrum, a previously presented HiKE-IMS-MS setup has been used ${ }^{9}$.

\section{Influence of the reduced electric field strength}

Figure $5 \mathrm{a}$ exhibits the recorded reactant ion spectra at a sample gas humidity of $70 \mathrm{ppm}_{\mathrm{v}}$ and a pressure of $14.3 \mathrm{mbar}$ for different reduced electric field strengths in the reaction region. The resulting relative abundances of the different ion species in dependence on the reduced electric field strength are shown in Figure 5b. Additionally, the relative abundances predicted by the kinetic model described in the previous section are plotted. To model the dependence of the relative abundances on the reduced electric reaction field strength, the calculated time interval is adjusted according to the dwell time of the ions in the reaction region of the HiKE-IMS. At every simulated time step, an average reduced ion mobility of all occurring ion species is used to estimate the drift length covered by the ions.
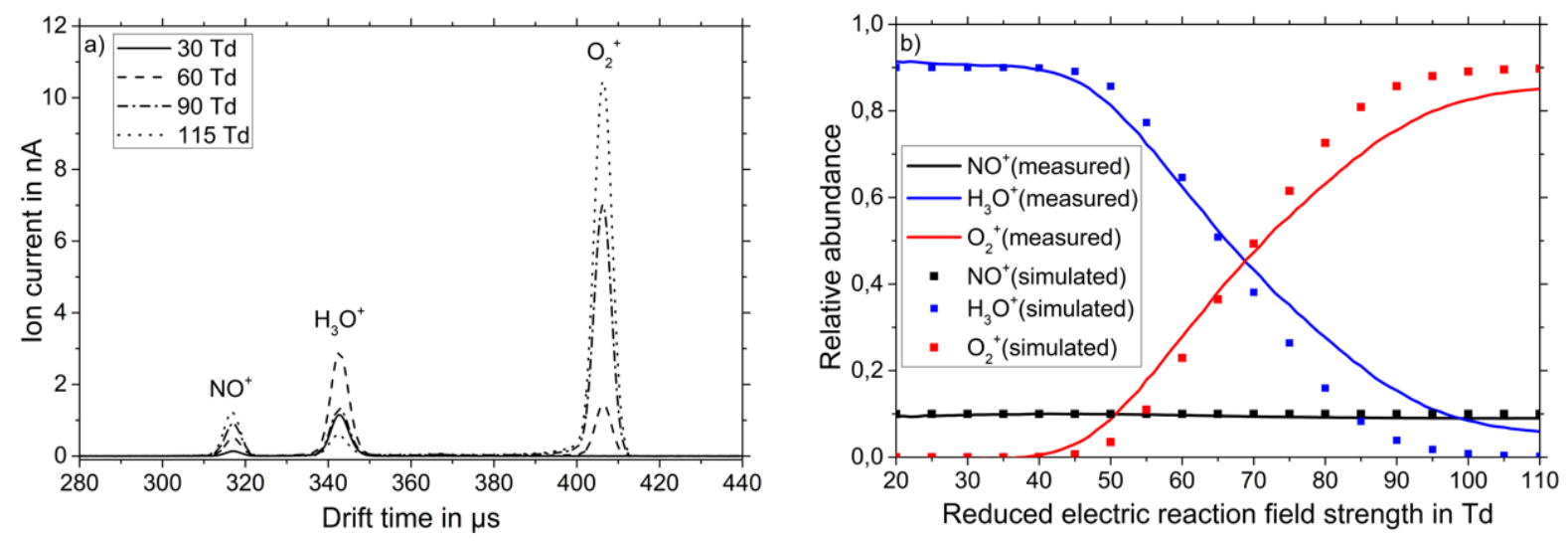

Figure 5: Variation of the reduced electric reaction field strength at a constant reduced electric drift field strength of $115 \mathrm{Td}$, a sample and drift gas humidity of $70 \mathrm{ppm}_{v}$ and a pressure of 14.3 mbar. a) lon mobility spectra at different reduced electric reaction field strengths, $b$ ) measured and simulated relative abundances of the ion species forming the ion mobility spectra in dependence on the reduced electric reaction field strength. 
In good accordance with the kinetic model, $\mathrm{H}_{3} \mathrm{O}^{+}, \mathrm{O}_{2}{ }^{+}$, and $\mathrm{NO}^{+}$occur in the recorded ion mobility spectra as a function of the reduced electric reaction field strength. At a reduced electric reaction field strength of $20 \mathrm{Td}$, only $\mathrm{H}_{3} \mathrm{O}^{+}$and $\mathrm{NO}^{+}$are observed in the ion mobility spectrum. Increasing the reduced electric reaction field strength, the conversion of $\mathrm{O}_{2}^{+}$to $\mathrm{H}^{+}\left(\mathrm{H}_{2} \mathrm{O}\right)_{n}$ is increasingly inhibited. Thus, at reduced electric field strengths exceeding $40 \mathrm{Td}$, the relative abundance of $\mathrm{O}_{2}{ }^{+}$in the ion mobility spectrum increases while the relative abundance of $\mathrm{H}_{3} \mathrm{O}^{+}$decreases. At reduced electric field strengths exceeding $105 \mathrm{Td}$, the conversion of $\mathrm{O}_{2}{ }^{+}$to $\mathrm{H}^{+}\left(\mathrm{H}_{2} \mathrm{O}\right)_{n}$ is almost entirely inhibited, resulting in the visible saturation of the relative abundance of $\mathrm{O}_{2}{ }^{+}$. However, in contrast to the results predicted by the kinetic model, at $110 \mathrm{Td}, \mathrm{H}_{3} \mathrm{O}^{+}$is still observed in the recorded ion mobility spectrum. This deviation may be due to several reasons. For example, modelling the field-dependence of the reaction system using the van't Hoff approach is only valid in a limited temperature interval. Furthermore, the reduced ion mobilities are only rough estimates from the ion masses. Additionally, the residence times of the ions in the reaction region is estimated based on an average reduced ion mobility. Nonetheless, the results of the kinetic model are in good agreement with the measurements and enable a qualitative interpretation.

\section{Influence of the sample gas humidity}

In Figure 6a, the recorded reactant ion spectra at constant reduced electric reaction field strength of $115 \mathrm{Td}$, constant pressure of $14.3 \mathrm{mbar}$ and variable sample gas humidity are shown. The sample gas humidity is given as relative sample gas humidity $(\mathrm{rH})$ at $298 \mathrm{~K}$ and $1013 \mathrm{mbar}$. It is noteworthy that the actual water concentration in the reaction region is about half the relative sample gas humidity due to mixing the sample gas in the reaction region with comparably dry drift gas. Increasing the sample gas humidity, the measured and simulated relative abundance of $\mathrm{O}_{2}^{+}$in the spectra decreases, as depicted in Figure $6 \mathrm{~b}$. This is explained by an increasing cluster association rate favoring the conversion of $\mathrm{O}_{2}^{+}$to protonated water clusters.


Figure 6: Variation of the relative sample gas humidity at constant reduced electric drift field strength of $110 \mathrm{Td}$, constant reduced electric reaction field strength of $115 \mathrm{Td}$ and constant pressure of $14.3 \mathrm{mbar}$. a) lon mobility spectra at different relative sample gas humidities, b) measured and simulated relative abundances of the ion species in the ion mobility spectra in dependence on the relative sample gas humidity. The relative sample gas humidity (rH) refers to $298 \mathrm{~K}$ and $1013 \mathrm{mbar}$.

Comparing the influence of the reduced electric reaction field strength on the ion formation mechanisms at four different relative sample gas humidities in Figure 7, this effect is also apparent. As elevated sample gas humidities favor the formation of water clusters, the minimum field strength required to inhibit the conversion of $\mathrm{O}_{2}{ }^{+}$to $\mathrm{H}^{+}\left(\mathrm{H}_{2} \mathrm{O}\right)_{n}$ increases with increasing sample gas humidity. At a water concentration of $70 \mathrm{ppm}_{\mathrm{v}}(0.35 \% \mathrm{rH}), \mathrm{O}_{2}{ }^{+}$can be observed at a reduced electric field strength above $40 \mathrm{Td}$. At a water concentration of $600 \mathrm{ppm}_{\mathrm{v}}(3 \% \mathrm{rH}), 60 \mathrm{Td}$ is required to observe $\mathrm{O}_{2}{ }^{+}$in the spectrum, at $1500 \mathrm{ppm}_{\mathrm{v}}(7 \% \mathrm{rH}), 80 \mathrm{Td}$ is required and with $4500 \mathrm{ppm}_{\mathrm{v}}(22 \% \mathrm{rH})$ water concentration, $\mathrm{O}_{2}{ }^{+}$is barely visible in the spectra even at $115 \mathrm{Td}$. A similar effect is observed considering the relative abundance of $\mathrm{NO}^{+}$. For example, at a water concentration in the sample gas of $4500 \mathrm{ppm}_{\mathrm{v}}, \mathrm{NO}^{+}$does 
not occur in the ion mobility spectrum at a reduced electric field strength of $20 \mathrm{Td}$. Here, a minimum field strength of $40 \mathrm{Td}$ is required to inhibit the conversion of $\mathrm{NO}^{+}$to $\mathrm{H}^{+}\left(\mathrm{H}_{2} \mathrm{O}\right)_{n}$. Comparing the measurements with the values predicted by the kinetic model, it is noteworthy that the influence of the sample gas humidity is underestimated in the model. As stated above, this might be due to the rather rough estimates used in the model. Nonetheless, the kinetic model is in good qualitative agreement with the measurements.

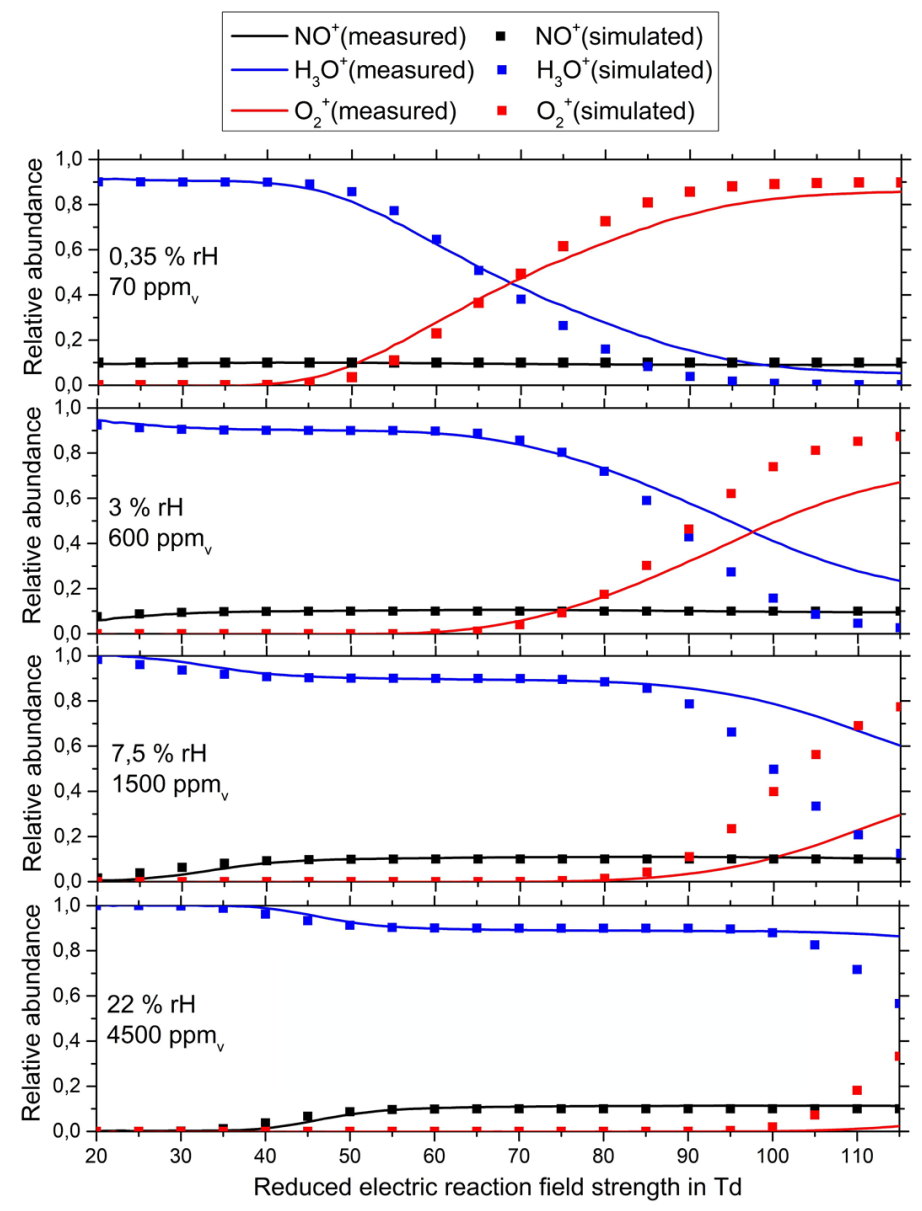

Figure 7: Variation of the reduced electric reaction field strength at four different sample gas humidities at constant reduced electric drift field strength of $115 \mathrm{Td}$ and constant pressure of $14.3 \mathrm{mbar}$. Measured and simulated relative abundances are plotted.

To assess the humidity dependence of the ionization of certain analytes in the HiKE-IMS, the results depicted in Figure 7 are highly relevant. Due to the significant change of the reactant ion population when increasing the relative sample gas humidity from $0.35 \% \mathrm{rH}$ to $20 \% \mathrm{rH}$, a strong dependence of the ionization pathways on the water content of the sample gas is expected. However, when operating the HiKE-IMS in field applications using a direct sample gas inlet, the relative humidity of the sample gas typically ranges between $20 \% \mathrm{rH}$ and $80 \% \mathrm{rH}$. In this range, the variation of the reactant ion population is small. At such conditions, $\mathrm{O}_{2}{ }^{+}$is rapidly converted into $\mathrm{H}^{+}\left(\mathrm{H}_{2} \mathrm{O}\right)_{n}$ that dissociate to $\mathrm{H}_{3} \mathrm{O}^{+}$at reduced electric reaction field strength exceeding $100 \mathrm{Td}$. Thus, between $20 \% \mathrm{rH}$ and $80 \% \mathrm{rH}$, the humidity dependence of the reactant ion population is low. To decrease the humidity dependence even further, it is possible to intentionally add a constant amount of water vapor close to the tip of the corona needle, as utilized in the first HiKE-IMS setup ${ }^{1}$ and as known from PTR-MS ${ }^{5}$. This water vapor promotes the conversion of $\mathrm{O}_{2}{ }^{+}$to $\mathrm{H}^{+}\left(\mathrm{H}_{2} \mathrm{O}\right)_{n}$. Furthermore, the water content in the reaction region is mainly governed by this added amount of water and thus the influence of sample gas humidity is further decreased if not eliminated. 


\section{Influence of the operating pressure}

In Figure 8, the influence of the reduced electric reaction field strength on the ion formation mechanisms are compared between the three different operating pressures $14.3 \mathrm{mbar}, 17.5 \mathrm{mbar}$ and 21.3 mbar. The water concentration in the sample gas is kept constant at $70 \mathrm{ppm}_{\mathrm{v}}$. Unfortunately, in the current setup, it is not possible to expand the investigations to a larger pressure range. However, as predicted by the kinetic model, these measurements already illustrates very well that an elevation of the operating pressure favors cluster association reactions. The reduced electric reaction field strength required to observe $\mathrm{O}_{2}{ }^{+}$in the spectrum increases when increasing the operating pressure from 14.3 mbar to 21.3 mbar.

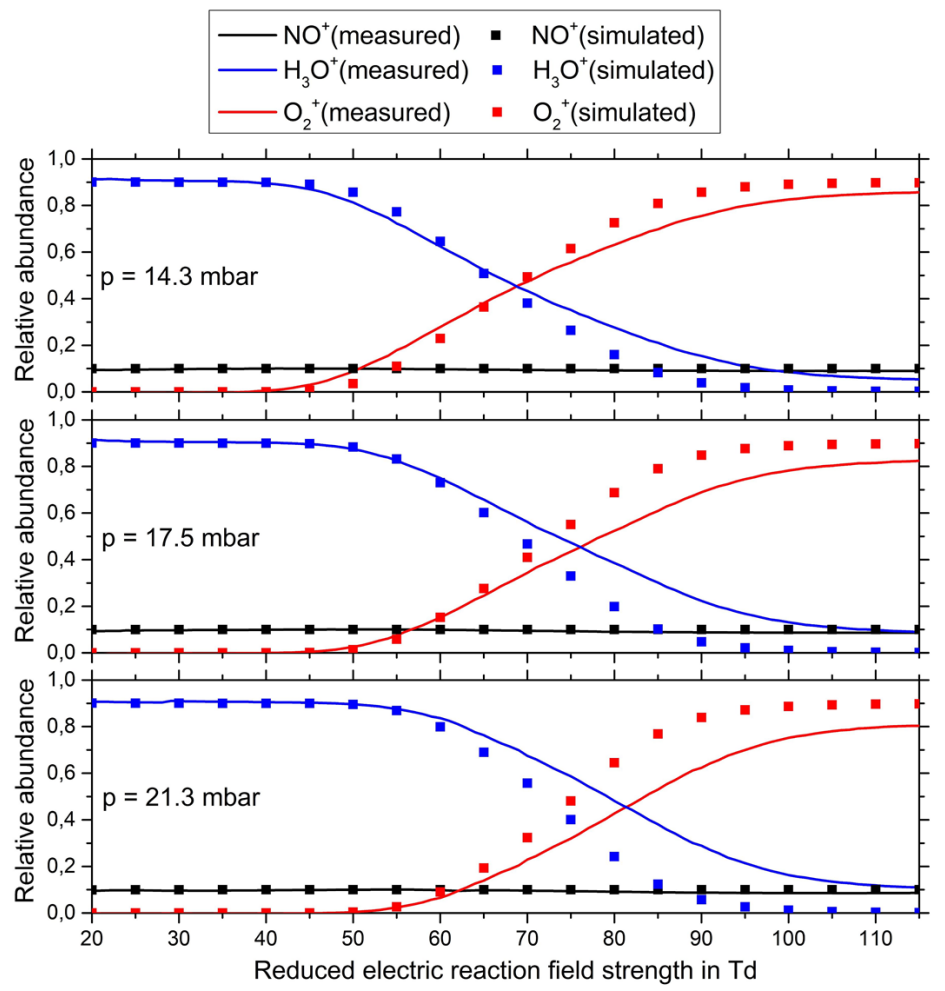

Figure 8: Variation of the reduced electric reaction field strength at three different operating pressure at constant reduced electric drift field strength of $115 \mathrm{Td}$ and constant sample gas humidity of $70 \mathrm{ppm}_{\mathrm{v}}$. Measured and simulated relative abundances are plotted.

\section{Origin of nitrogen oxides}

In addition to $\mathrm{NO}^{+}\left(\mathrm{H}_{2} \mathrm{O}\right)_{n}$, under certain conditions also small amounts of $\mathrm{NO}_{2}^{+}\left(\mathrm{H}_{2} \mathrm{O}\right)_{n}$ occur in the HiKEIMS spectrum. The origin of these cations has been discussed thoroughly in the literature ${ }^{49-51}$. In particular, with a corona discharge ionization source, nitrogen oxide cations have been observed. Usually, the collision of energetic electrons with neutral $\mathrm{N}_{2}$ or $\mathrm{O}_{2}$ molecules results in the production of $\mathrm{N}_{2}{ }^{+}$or $\mathrm{O}_{2}{ }^{+}$cations. However, in some cases also a dissociation of $\mathrm{N}_{2}$ or $\mathrm{O}_{2}$ in the excited radicals $\mathrm{N}$ or $\mathrm{O}$ occurs ${ }^{52,53}$. These radicals can react to $\mathrm{NO}^{+}$according to the following reactions ${ }^{38}$.

$$
\begin{gathered}
\mathrm{N}_{2}{ }^{+}+\mathrm{O} \rightarrow \mathrm{NO}^{+}+\mathrm{N} \\
\mathrm{N}+\mathrm{O}+\mathrm{M} \rightarrow \mathrm{NO}+\mathrm{M} \\
\mathrm{N}_{2}{ }^{+}+\mathrm{NO} \rightarrow \mathrm{NO}^{+}+\mathrm{N}_{2}
\end{gathered}
$$

However, the abundance of $\mathrm{NO}^{+}$significantly depends on the operating parameters of the corona discharge ionization source. It has been shown for example, that the $\mathrm{NO}^{+}$abundance is a function of the corona discharge current ${ }^{50,54}$ and the reverse flow rate ${ }^{22}$. In the HiKE-IMS, these dependencies are 
also observed. As shown in Figure 9, the relative abundance of $\mathrm{NO}^{+}$and $\mathrm{NO}_{2}^{+}$in the spectrum increases with increasing corona discharge current and decreases with increasing reverse flow rate. In particular, the latter implies the important role of radicals and neutrals in the formation of $\mathrm{NO}^{+}$and $\mathrm{NO}_{2}{ }^{+}$in the HiKE-IMS.
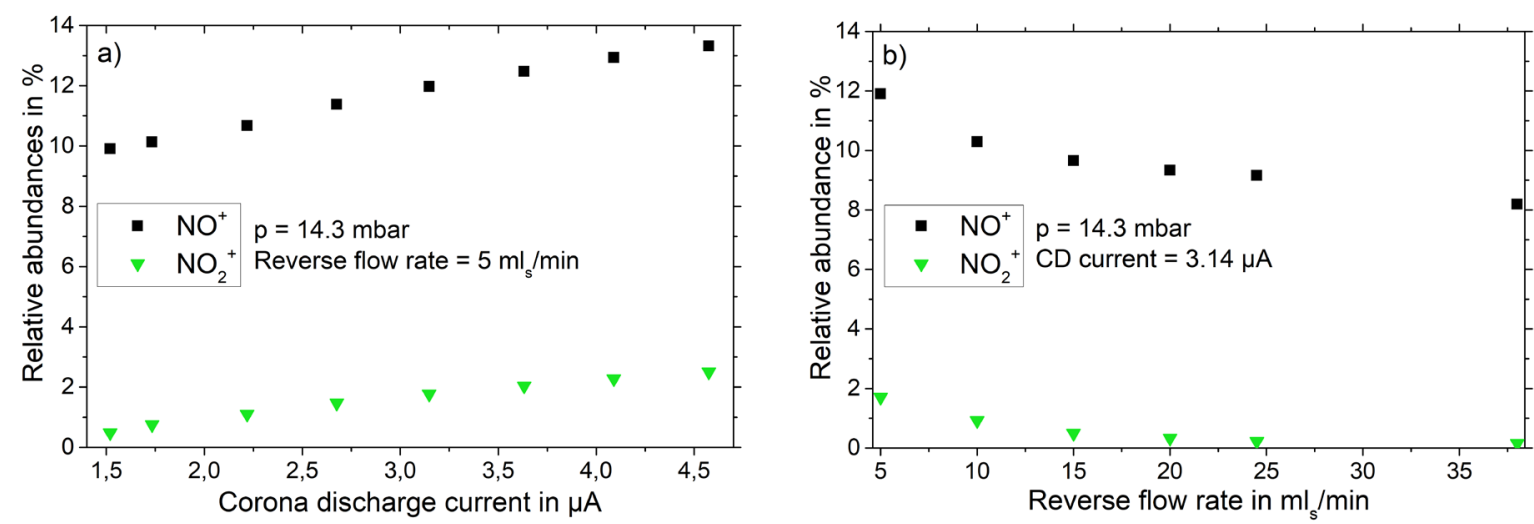

Figure 9: Measured relative abundances of $\mathrm{NO}^{+}$and $\mathrm{NO}_{2}{ }^{+}$in the HiKE-IMS spectrum in dependence on the corona discharge $(C D)$ current and the reverse flow rate. a) Variation of the corona discharge current by altering the corona discharge voltage from $1000 \mathrm{~V}$ and $1400 \mathrm{~V}$, corresponding to an effective corona discharge voltage of $864 \mathrm{~V}$ and $941 \mathrm{~V}$ between the needle tip and grid electrode considering the $100 \mathrm{MOhm}$ series resistor. b) Variation of the reverse flow rate at constant pressure by altering the drift gas flow while adjusting the pumping rate. The measurements are performed at constant reduced electric reaction and drift field strength of $115 \mathrm{Td}$, the sample gas flow is zero, the relative humidity of the drift gas is $3 \%$.

\section{Conclusion}

In this work, we investigated the mechanisms leading to the formation of positive reactant ions in HiKEIMS. Based on kinetic and thermodynamic data from the literature, we developed a model describing the underlying ion-molecule reactions. This model is in good agreement with measurements at various operating pressures, sample gas humidities, and reduced electric field strengths. The reactant ion population in the HiKE-IMS is mainly determined by the conversion processes of $\mathrm{O}_{2}^{+}$and $\mathrm{NO}^{+}$to protonated water clusters $\mathrm{H}^{+}\left(\mathrm{H}_{2} \mathrm{O}\right)_{n}$. Increasing the reduced electric field strength inhibits these conversion processes, whereas increasing the operating pressure and the sample gas water humidity favors the formation of $\mathrm{H}^{+}\left(\mathrm{H}_{2} \mathrm{O}\right)_{n}$. Thus, the relative abundances of $\mathrm{O}_{2}{ }^{+}, \mathrm{NO}^{+}$and $\mathrm{H}^{+}\left(\mathrm{H}_{2} \mathrm{O}\right)_{n}$ strongly depends on the operating conditions. The findings obtained in this study are not only useful for HiKEIMS coupled to corona discharge ionization sources. The investigated ion-molecule reactions might also be relevant in other devices such as PTR-MS or SIFDT-MS.

\section{Acknowledgment}

This work was funded by the Deutsche Forschungsgemeinschaft (DFG, German Research Foundation), joint project BE 2124/8-1 - ZI 1288/8-1 


\section{References}

(1) Langejuergen, J.; Allers, M.; Oermann, J.; Kirk, A. T.; Zimmermann, S. High kinetic energy ion mobility spectrometer: quantitative analysis of gas mixtures with ion mobility spectrometry. Analytical chemistry 2014, 86, 7023-7032.

(2) Langejuergen, J.; Allers, M.; Oermann, J.; Kirk, A. T.; Zimmermann, S. Quantitative detection of benzene in toluene- and xylene-rich atmospheres using high-kinetic-energy ion mobility spectrometry (IMS). Analytical chemistry 2014, 86, 11841-11846.

(3) Kirk, A. T.; Grube, D.; Kobelt, T.; Wendt, C.; Zimmermann, S. High-Resolution High Kinetic Energy Ion Mobility Spectrometer Based on a Low-Discrimination Tristate Ion Shutter. Analytical chemistry 2018, 90, 5603-5611.

(4) Wannier, G. H. Motion of Gaseous Ions in Strong Electric Fields. Bell System Technical Journal 1953, 32, 170-254.

(5) Ellis, A. M.; Mayhew, C. A. Proton Transfer Reaction Mass Spectrometry; John Wiley \& Sons, Ltd: Chichester, UK, 2014.

(6) Shvartsburg, A. A. Differential ion mobility spectrometry; CRC Press: Boca Raton, 2009.

(7) Chiluwal, U.; Lee, G.; Rajapakse, M. Y.; Willy, T.; Lukow, S.; Schmidt, H.; Eiceman, G. A. Tandem ion mobility spectrometry at ambient pressure and field decomposition of mobility selected ions of explosives and interferences. The Analyst 2019, 144, 2052-2061.

(8) Bohnhorst, A.; Kirk, A. T.; Yin, Y.; Zimmermann, S. Ion Fragmentation and Filtering by Alpha Function in Ion Mobility Spectrometry for Improved Compound Differentiation. Anal. Chem. 2019, 91, 8941-8947.

(9) Allers, M.; Kirk, A. T.; Roßbitzky, N. von; Erdogdu, D.; Hillen, R.; Wissdorf, W.; Benter, T.; Zimmermann, S. Analyzing Positive Reactant Ions in High Kinetic Energy lon Mobility Spectrometry (HiKE-IMS) by HiKE-IMS-MS. Journal of the American Society for Mass Spectrometry 2020, 31, 812821.

(10) Allers, M.; Kirk, A. T.; Timke, B.; Erdogdu, D.; Wissdorf, W.; Benter, T.; Zimmermann, S. Negative Reactant Ion Formation in High Kinetic Energy Ion Mobility Spectrometry (HiKE-IMS). Journal of the American Society for Mass Spectrometry 2020, Under review.

(11) Cheng, H.-P. Water Clusters: Fascinating Hydrogen-Bonding Networks, Solvation Shell Structures, and Proton Motion. J. Phys. Chem. A 1998, 102, 6201-6204.

(12) Goebbert, D. J.; Wentold, P. G. Water dimer proton affinity from the kinetic method: dissociation energy of the water dimer. European journal of mass spectrometry (Chichester, England) 2004, 10, 837-846.

(13) Mayer, T.; Borsdorf, H. Accuracy of ion mobility measurements dependent on the influence of humidity. Analytical chemistry 2014, 86, 5069-5076.

(14) Eiceman GA, Nazarov EG, Rodriguez JE, Bergloff JF. Positive Reactant lon Chemistry for Analytical, High Temperaturelon Mobility Spectrometry (IMS): Effects of Electric Field of the DriftTube and Moisture, Temperature, and Flow of the Drift Gas. Int. J. Ion Mobil. Spec. 1998, 28-37. (15) Tabrizchi, M.; Rouholahnejad, F. Comparing the effect of pressure and temperature on ion mobilities. Anal. Chem. 2005, 38, 857-862.

(16) Fernandez-Maestre, R.; Meza-Morelos, D.; Wu, C. Mobility shifts when buffer gas temperature increases in ion mobility spectrometry are affected by intramolecular bonds. International Journal of Mass Spectrometry 2016, 407, 113-117.

(17) Mäkinen, M.; Sillanpää, M.; Viitanen, A.-K.; Knap, A.; Mäkelä, J. M.; Puton, J. The effect of humidity on sensitivity of amine detection in ion mobility spectrometry. Talanta 2011, 84, 116-121. (18) Izadi, Z.; Tabrizchi, M.; Borsdorf, H.; Farrokhpour, H. Humidity Effect on the Drift Times of the Reactant Ions in Ion Mobility Spectrometry. Analytical chemistry 2019, 91, 15932-15940. 
(19) Španěl, P.; Smith, D. Selected ion flow tube studies of the reactions of $\mathrm{H} 3 \mathrm{O}+$, NO+, and $\mathrm{O} 2+$ with several aromatic and aliphatic hydrocarbons. International Journal of Mass Spectrometry 1998, 181, $1-10$.

(20) Španěl, P.; Ji, Y.; Smith, D. SIFT studies of the reactions of $\mathrm{H} 3 \mathrm{O}+, \mathrm{NO}+$ and $\mathrm{O} 2+$ with a series of aldehydes and ketones. International Journal of Mass Spectrometry and Ion Processes 1997, 165-166, 25-37.

(21) Španěl, P.; Smith, D. SIFT studies of the reactions of $\mathrm{H} 3 \mathrm{O}+, \mathrm{NO}+$ and $\mathrm{O} 2+$ with several ethers. International Journal of Mass Spectrometry and Ion Processes 1998, 172, 239-247.

(22) Ross, S. K.; Bell, A. J. Reverse flow continuous corona discharge ionisation applied to ion mobility spectrometry. International Journal of Mass Spectrometry 2002, 218, L1-L6.

(23) Shahin, M. M. Mass-Spectrometric Studies of Corona Discharges in Air at Atmospheric Pressures. The Journal of Chemical Physics 1966, 45, 2600-2605.

(24) Shahin, M. M. Use of Corona Discharges for the Study of Ion-Molecule Reactions. The Journal of Chemical Physics 1967, 47, 4392-4398.

(25) Good, A.; Durden, D. A.; Kebarle, P. Ion-Molecule Reactions in Pure Nitrogen and Nitrogen Containing Traces of Water at Total Pressures 0.5-4 torr. Kinetics of Clustering Reactions Forming $\mathrm{H}+$ (H 2 O) n. The Journal of Chemical Physics 1970, 52, 212-221.

(26) McCrumb, J. L.; Warneck, P. On the mechanism of water cluster-ion formation in nitrogen. The Journal of Chemical Physics 1977, 67, 5006-5011.

(27) Cunningham, A. J.; Payzant, J. D.; Kebarle, P. Kinetic study of the proton hydrate $\mathrm{H}+(\mathrm{H} 2 \mathrm{O}) \mathrm{n}$ equilibriums in the gas phase. J. Am. Chem. Soc. 1972, 94, 7627-7632.

(28) Lau, Y. K.; Ikuta, S.; Kebarle, P. Thermodynamics and kinetics of the gas-phase reactions $\mathrm{H} 3 \mathrm{O}+(\mathrm{H} 2 \mathrm{O}) \mathrm{n}-1+$ water $=\mathrm{H} 3 \mathrm{O}+(\mathrm{H} 2 \mathrm{O})$ n. J. Am. Chem. Soc. 1982, 104, 1462-1469.

(29) Gouw, J. de; Warneke, C.; Karl, T.; Eerdekens, G.; van der Veen, C.; Fall, R. Sensitivity and specificity of atmospheric trace gas detection by proton-transfer-reaction mass spectrometry. International Journal of Mass Spectrometry 2003, 223-224, 365-382.

(30) Fehsenfeld, F. C.; Schmeltekopf, A. L.; Ferguson, E. E. Thermal-Energy Ion-Neutral Reaction Rates. VII. Some Hydrogen-Atom Abstraction Reactions. The Journal of Chemical Physics 1967, 46, 2802-2808.

(31) Ferguson, E. E.; Fehsenfeld, F. C. Water vapor ion cluster concentrations in the D region. J. Geophys. Res. 1969, 74, 5743-5751.

(32) Fehsenfeld, F. C.; Ferguson, E. E. Origin of water cluster ions in the D region. J. Geophys. Res. 1969, 74, 2217-2222.

(33) Good, A.; Durden, D. A.; Kebarle, P. Mechanism and Rate Constants of Ion-Molecule Reactions

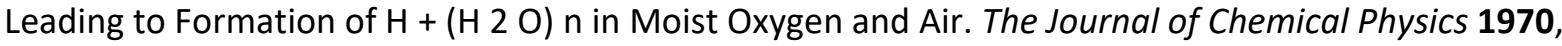
52, 222-229.

(34) Payzant, J. D.; Cunningham, A. J.; Kebarle, P. Temperature dependence of the rate constants for the third order reactions: $\mathrm{O} 2++2 \mathrm{O} 2=04++02$ and $04++2 \mathrm{O} 2=06++02$. The Journal of Chemical Physics 1973, 59, 5615-5619.

(35) Payzant, J. D.; Kebarle, P. Kinetics of Reactions Leading to O 2- (H 2 O) n in Moist Oxygen. The Journal of Chemical Physics 1972, 56, 3482-3487.

(36) Raksit, A. B.; Warneck, P. A drift chamber study of the formation of water cluster ions in oxygen. The Journal of Chemical Physics 1980, 73, 5074-5080.

(37) Raksit, A. B. Reactions of $\mathrm{O} 2+, \mathrm{O} 4+$ and $\mathrm{O} 2+\cdot \mathrm{H} 2 \mathrm{O}$ ions with neutral molecules. International Journal of Mass Spectrometry and Ion Processes 1986, 69, 45-65.

(38) Pavlik, M.; Skalny, J. D. Generation of [H3O]+.(H2O)n clusters by positive corona discharge in air. Rapid Commun. Mass Spectrom. 1997, 11, 1757-1766. 
(39) Howard, C. J.; Bierbaum, V. M.; Rundle, H. W.; Kaufman, F. Kinetics and Mechanism of the Formation of Water Cluster lons from O2+ and H 2 O. The Journal of Chemical Physics 1972, 57, 3491-3497.

(40) Howard, C. J.; Rundle, H. W.; Kaufman, F. Water Cluster Formation Rates of NO + in He, Ar, N 2, and $O 2$ at $296^{\circ} \mathrm{K}$. The Journal of Chemical Physics 1971, 55, 4772-4776.

(41) Angel, L.; Stace, A. J. The critical hydration reactions of NO+ and NO2+. The Journal of Chemical Physics 1998, 109, 1713-1715.

(42) French, M. A.; Hills, L. P.; Kebarle, P. Kinetics and Temperature Dependence of the Hydration of $\mathrm{NO}+$ in the Gas Phase. Can. J. Chem. 1973, 51, 456-461.

(43) Viehland, L. A. Gaseous Ion Mobility, Diffusion, and Reaction; Springer International Publishing: Cham, 2018.

(44) Atkins, P. W.; Paula, J. de; Keeler, J. Atkins' physical chemistry; Oxford University Press: Oxford, New York, 2018.

(45) Appelhans, A. D.; Dahl, D. A. SIMION ion optics simulations at atmospheric pressure. International Journal of Mass Spectrometry 2005, 244, 1-14.

(46) Hiraoka, K.; Nakajima, G. A determination of the stabilities of $N+2$ (N 2 ) n and O +2 (N 2 ) n with $\mathrm{n}=1-11$ from measurements of the gas-phase ion equilibria. The Journal of Chemical Physics 1988, $88,7709-7714$.

(47) Sharma, S.; Wright, T. G.; Besley, N. A. Reactivity of the $\mathrm{O} 2+\cdot(\mathrm{H} 2 \mathrm{O}) \mathrm{n}$ and $\mathrm{NO}+\cdot(\mathrm{H} 2 \mathrm{O})$ n cluster ions in the D-region of the ionosphere. Physical chemistry chemical physics : PCCP 2018, 20, 25931-25938.

(48) Fehsenfeld, F. C.; Mosesman, M.; Ferguson, E. E. Ion-Molecule Reactions in an O $2+-\mathrm{H} 2 \mathrm{O}$ System. The Journal of Chemical Physics 1971, 55, 2115-2120.

(49) Chen, J.; Wang, P. Effect of relative humidity on electron distribution and ozone production by DC coronas in air. IEEE Trans. Plasma Sci. 2005, 33, 808-812.

(50) Skalný, J.; Hortváth, G.; Mason, N. J. Spectra of Ions Produced by Corona Discharges. AIP Conference Proceedings 2006, 867 2006, 284-293.

(51) Sabo, M.; Klas, M.; Wang, H.; Huang, C.; Chu, Y.; Matejčík, Š. Positive corona discharge ion source with IMS/MS to detect impurities in high purity Nitrogen. Eur. Phys. J. Appl. Phys. 2011, 55, 13808.

(52) Itikawa, Y. Cross Sections for Electron Collisions with Nitrogen Molecules. Journal of Physical and Chemical Reference Data 2006, 35, 31-53.

(53) Itikawa, Y. Cross Sections for Electron Collisions with Oxygen Molecules. Journal of Physical and Chemical Reference Data 2009, 38, 1-20.

(54) Sekimoto, K.; Takayama, M. Influence of needle voltage on the formation of negative core ions using atmospheric pressure corona discharge in air. International Journal of Mass Spectrometry 2007, $261,38-44$. 